\section{AB010. Keloidal scleroderma with isolated intertriginous involvement}

\author{
Vijay Balakrishnan, Lauren V. Graham, \\ Lauren C. S. Kole
}

Department of Dermatology, University of Alabama at Birmingham, Birmingham, AL, USA

Correspondence to: Lauren C. S. Kole. Dept. of Dermatology Suite 858, Birmingham, 510 20th Street South, Birmingham, AL, USA. Email: laurenkole@uabmc.edu.

\begin{abstract}
A 33-year-old African-American female with scleroderma, Raynaud phenomenon, and possible systemic lupus erythematosus (SLE) presented to dermatology clinic for evaluation of a 1-year history of slowly growing plaques in her bilateral axillae and inguinal region. The patient was initially diagnosed with scleroderma approximately five years prior to presentation following the onset of sclerodactyly, arthralgias, myalgias, and severe obstructive lung disease. Two years prior to presentation, she was started on monthly intravenous immunoglobulin infusions. Her other medications included hydroxychloroquine, mycophenolic acid, cilostazol, and amlodipine. One year ago, she began developing leathery, firm, dark plaques underneath both armpits. The plaques slowly enlarged and new plaques began forming in her inguinal region. They were nonpruritic but mildly tender. On exam, the patient had well-demarcated, linear, hyperpigmented, indurated plaques that coalesced in her bilateral axillae, bilateral inguinal folds, and bilateral peri-inguinal region with no evident secondary scale or crust. She also had sclerodactyly of the digits of her bilateral hands and blue-
\end{abstract}

white discoloration of her $4^{\text {th }}$ digit of the right hand. A $4 \mathrm{~mm}$ punch biopsy was performed from her left axilla and was consistent with keloidal morphea/scleroderma. Keloidal scleroderma, also known as nodular scleroderma, is a rare manifestation of systemic sclerosis that is usually characterized by innumerable nodules or keloidal plaques on the trunk. We present a case of isolated intertriginous keloidal scleroderma, an exceedingly uncommon distribution for this condition. A recent literature review of nodular scleroderma by Kassira et al. revealed only one reported case with lesions in intertriginous areas. Given the rarity of the diagnosis, our knowledge of efficacious treatment options remains limited. Possible options for treatment include methotrexate, ultraviolet A light therapy, and narrow-band ultraviolet B light therapy. Teaching point: the patient's biopsy-proven isolated intertriginous keloidal scleroderma represents an uncommon clinical presentation for an already rare variant of systemic sclerosis.

Keywords: Keloidal scleroderma; keloidal morphea; nodular scleroderma

doi: 10.21037/atm.2021.AB010

Open Access Statement: This is an Open Access article distributed in accordance with the Creative Commons Attribution-NonCommercial-NoDerivs 4.0 International License (CC BY-NC-ND 4.0), which permits the noncommercial replication and distribution of the article with the strict proviso that no changes or edits are made and the original work is properly cited (including links to both the formal publication through the relevant DOI and the license). See: https://creativecommons.org/licenses/by-nc-nd/4.0/.

Cite this abstract as: Balakrishnan V, Graham LV, Kole LCS. Keloidal scleroderma with isolated intertriginous involvement. Ann Transl Med 2021;9(5):AB010. doi: 10.21037/atm.2021.AB010 